hoặc quan trọng hơn, cải thiện tiên lượng cho bệnh nhân. Thống nhất với các nghiên cứu trước đầy, chúng tôi ủng hộ dẫn lưu cả hai nguồn nhiếm khuẩn và mủ nội sọ và kết hợp kháng sinh liệu pháp sẽ giảm tình trạng bệnh, tỷ lệ tử vong và tỷ lệ tái phát [1].

Nếu xương xoang trán bị hoại tử dẫn đến viêm xương, loại bỏ vùng nhiễm trùng bao gồm áp xe cốt mạc, xương viêm, áp xe ngoài màng cứng, và mô hat được khuyến nghị. Hơn nữa, cố gắng cắt và kiểm tra thành sau của xoang trán [3]. Khi loại bỏ mô hạt viêm từ màng cứng, chú ý tránh là̀m thủng và đưa nhiễm trùng vào khoang dưới màng cứng. Tỷ lệ tử vong khoảng $30 \%$ ở những bệnh nhân tụ mủ dưới màng cứng, trong khi đó áp xe ngoài màng cứng tách biệt có thể được điều trị không có tử vong [7]. Mắt khác, mở sọ của xương trán có tính thẩm mỹ và ngày nay được xem không cần thiết khi xương trán bị mòn có khả năng lành $6-8$ tuần dùng liệu pháp kháng sinh.

\section{KẾT LUÂN:}

Viêm xoang biến chứng áp xe não ngày nay ít gặp do sự phát triển và sử dụng kháng sinh rộng rãi. Tuy nhiên, khi xảy ra thì nguy hiếm đến tính mạng. Cần chẩn đoán sớm và điêu trị thích hợp kháng sinh theo kinh nghiệm trước, thâm chí kết hợp với phẫu thuật nội qua qua mũi hoặc mở não để dẫn lưu ổ mủ trong não là phương pháp triệt để giải quyết áp xe não do xoang , giúp bệnh nhân hồi phục sớm, giảm tỷ lệ biến chứng.
TÀI LIẸU THAM KHẢO

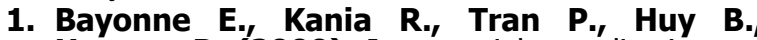
Herman P. (2009), Intracranial complications of rhinosinusitis. A review, typical imaging data and algorithm of management. Rhinology, 47(1), 59-65.

2. Brook I. (2002), Bacteriology of acute and chronic frontal sinusitis. Arch Otolaryngol Head Neck Surg, 128 (5), 583-5.

3. Clayman G. L., Adams G. L., Paugh D. R., Koopmann C. F., Jr. (1991), Intracranial complications of paranasal sinusitis: a combined institutional review. Laryngoscope, 101 (3), 234-9.

4. Germiller J. A., Monin D. L., Sparano A. M. Tom L. W. (2006), Intracranial complications of sinusitis in children and adolescents and their outcomes. Arch Otolaryngol Head Neck Surg, 132 (9), 969-76.

5. Hicks C. W., Weber J. G., Reid J. R., Moodley M. (2011), Identifying and managing intracranial complications of sinusitis in children: a retrospective series. Pediatr Infect Dis J, 30 (3), 222-6.

6. Kombogiorgas D., Seth R., Athwal R., Modha J., Singh J. (2007), Suppurative intracranial complications of sinusitis in adolescence. Single institute experience and review of literature. $\mathrm{Br}$ J Neurosurg, 21 (6), 603-9.

7. Legrand M., Roujeau T., Meyer P., Carli P., Orliaguet G., Blanot S. (2009), Paediatric intracranial empyema: differences according to age. Eur J Pediatr, 168 (10), 1235-41.

8. Muzumdar D., Jhawar S., Goel A. (2011), Brain abscess: an overview. Int J Surg, 9 (2), 136-44.

9. Nicoli T. K., Oinas M., Niemelä́ M., Mäkitie A A., Atula T. (2016), Intracranial Suppurative Complications of Sinusitis. Scand J Surg, 105 (4) 254-262.

10. Piatt J. H., Jr. (2011), Intracranial suppuration complicating sinusitis among children: an epidemiological and clinical study. J Neurosurg Pediatr, 7 (6), 567-74.

\title{
ĐIỀU TRI DUY TRÌ BẰNG OLAPARIB Ở BÊ̂NH NHÂN UNG THƯ BUỒNG TRỨNG TIẾN XA MỚI CHẨN ĐOÁN
}

Phạm Trí Hiếu ${ }^{1}$, Nguyễn Văn Thắng ${ }^{2}$, Trần Thị Thanh Huyền ${ }^{3}$

\section{TÓM TẮT}

Đặt vấn đề: Hầu hết phụ nữ ung thư buồng trứng (UTBT) giai đoạn tiến xa mới chẩn đoán, sau khi điêu trị chuân bằng phẫu thuật và hóa trị liệu có chứa Platinum sẽ tái phát trong 3 năm đầu. Olaparib là thuốc ức chế enzym poly (adenosine diphosphateribose) polymerase, có hiệu quả tốt trong điều trị ung

${ }^{1}$ Bênh viện Phụ sản Trung Uơng

${ }^{2}$ Bệnh viện Phù sản Trung Ương

${ }^{3}$ Trung tâm cống nghê cao - Bệnh viên Vinmec

Chịu trách nhiệm chính: Phạm Trí Hiểu

Email: Thongke8@gmail.com

Ngày nhận bài: 16.8.2021

Ngày phản biên khoa hoc: 18.10.2021

Ngày duyệt bài: 27.10.2021 thư buồng trứng tái phát, nhưng lơi ích của Olaparib trong điều trị duy trì đối với các trường hợp mới được chẩn đoán chưa được chứng minh. Phương pháp: Thử nghiệm lâm sàng pha 3, đa trung tâm, ngâu nhiên, mù đôi, nhằm đánh giá hiêu quả của Ólaparib như một liệu pháp duy trì ở những bệnh nhân mới được chẩn đoán ung thư buồng trứng giai đoan III IV theo FIGO; gôm các thể: ung thư biểu mồ thanh dich hoăc ung thư dang nội mac tử cung, đô ác tính cao, ung thư phúc mạc nguyên phát, ung thư vòi tử cung (hoăc các dang kết hợp), với đột biến ở gen BRCA1, BRCA2 hoặc cả hai; đã có đáp ứng lâm sàng hoàn toàn hoăc một phân sau khi hóa trị liệu bằng hóa trị có chứa Platinum. Các bênh nhân được chỉ định ngấu nhiên, theo tỷ lệ $2: 1$, được uống Olaparib (300mg hai lần mỗi ngày) hoặc giả dược. Tiêu chí 
chính của nghiên cứu là sống thêm bệnh không tiến triển (PFS). Kết quả: Trong số 391 bệnh nhân, sau chọn ngẫu nhiên có 260 người được chỉ định nhận Olaparib và 131 nhận giả dược. Tổng cộng 388 bệnh nhân có đột biến gen BRCA1/2 dạng di truyền (germline) và 2 bệnh nhân đột biến dạng mắc phải (somatic) được xác nhận bởi phòng xét nghiệm trung tâm. Sau khi theo dõi trung vị 41 tháng, nguy cơ bệnh tiến triển hoặc tử vong ở nhóm dùng Olaparib thấp hơn 70\% so với giả dước; tỷ số nguy cơ (HR) bệnh tiến triển hoặc tử vong là 0,$30 ;$ CI $95 \%$ [0,23-0,41], $\mathrm{p}<0,001)$. Các biến cố ngoai ý phù hợp với độc tính đã biết của Olaparib. Kết luận: Điều trị duy trì bằng Olaparib giúp cải thiện đáng kể thời gian sống thêm bênh không tiến triển ở phư nữ ung thư buồng trứng giai đoạn tiến xa mới chẩn đoán, có đột biến gen BRCA1/2; làm giảm 70\% nguy cơ tiến triển bệnh hoặc tử vong so với với giả dược.

\section{SUMMARY \\ MAINTENANCE OLAPARIB IN PATIENTS WITH NEWLY DIAGNOSED ADVANCED OVARIAN CANCER}

Background. Most women with newly diagnosed advanced ovarian cancer have a relapse within 3 years after standard treatment with surgery and platinumbased chemotherapy. The benefit of the oral poly(adenosine diphosphate-ribose) polymerase inhibitor olaparib in relapsed disease has been well established, but the benefit of olaparib as maintenance therapy in newly diagnosed disease is uncertain. Methods. We conducted an international, randomized, double-blind, phase 3 trial to evaluate the efficacy of olaparib as maintenance therapy in patients with newly diagnosed advanced (International Federation of Gynecology and Obstetrics stage III or IV) high-grade serous or endometrioid ovarian cancer, primary peritoneal cancer, or fallopian-tube cancer (or a combination thereof) with a mutation in BRCA1, BRCA2, or both (BRCA1/2) who had a complete or partial clinical response after platinumbased chemotherapy. The patients were randomly assigned, in a 2:1 ratio, to receive olaparib tablets $(300 \mathrm{mg}$ twice daily) or placebo. The primary end point was progression-free survival. Results. Of the 391 patients who underwent randomization, 260 were assigned to receive olaparib and 131 to receive placebo. A total of 388 patients had a centrally confirmed germline BRCA1/2 mutation, and 2 patients had a centrally confirmed somatic BRCA1/2 mutation. After a median follow-up of 41 months, the risk of disease progression or death was $70 \%$ lower with olaparib than with placebo (Kaplan-Meier estimate of the rate of freedom from disease progression and from death at 3 years, $60 \%$ vs. $27 \%$; hazard ratio for disease progression or death, $0.30 ; 95 \%$ confidence interval, 0.23 to $0.41 ; P<0.001)$. Adverse events were consistent with the known toxic effects of olaparib. Conclusions. The use of maintenance therapy with olaparib provided a substantial benefit with regard to progression-free survival among women with newly diagnosed advanced ovarian cancer and a BRCA1/2 mutation, with a $70 \%$ lower risk of disease progression or death with olaparib than with placebo.

\section{I. ĐĂT VẤN ĐỀ}

Trị liệu chuẩn cho bệnh nhân UTBT giai đoan tiến xa mới được chẩn đoán bao gồm: phẩu thuật làm giảm tổng khối bướu và hóa trị liệu có chứa Platinum. Mặc dù phần lớn không còn bằng chứng về ung thư sau điều trị, khoảng $70 \%$ số bệnh nhân sẽ bị tái phát trong vòng 3 năm tiếp theo.

Olaparib là thuốc thuộc nhóm chất ức chế enzyme poly(adenosine diphosphate - ribose) polymerase (PARPi). Việc ức chế PARP làm ngăn cản quá trình sửa chữa đứt gãy sợi đơn DNA, trong quá trình sao chép dẫn đến tích luỹ các đứt gãy sợi đôi. Các tế bào ung thư mà bị thiếu hụt chức năng sửa chữa tái tổ hợp tương đồng như tế bào ung thư có đột biến gen BRCA1/2 thì các đứt gãy sợi đôi không được sữa chữa một cách chính xác, từ đó dẫn đến tích lũy các tổn thương DNA, gây chết tế bào.

Điều trị duy trì bằng Olaparib cho phụ nữ bị UTBT tái phát nhạy Platinum đã được chấp thuận tại Hoa Kỳ, châu Âu cũng như Hội Ung thư quốc tế (NCCN). Olaparib cũng được chấp thuận tại Hoa Kỳ cho bệnh nhân UTBT giai đoạn tiến xa có đột biến BRCA di truyền dạng gây bệnh hoặc nghi ngờ gây bệnh đã được điều trị từ 3 phác đồ hóa chất trở lển bất kể có nhạy với hóa chất chứa platinum hay không.

\section{II. ĐỐI TƯỢNG VÀ PHƯƠNG PHÁP NGHIÊN CỨU}

Đối tượng nghiên cứu: Bệnh nhân $\geq 18$ tuổi, UTBT tiến xa (giai đoạn III, IV theo FIGO). Thể giải phẫu bệnh: ung thư biểu mô thanh dịch hoặc ung thư biểu mô tuyến dạng nội mạc tử cung độ ác tính cao; ung thư vòi tử cung, ung thư phúc mạc nguyên phát hoặc phối hợp. Bệnh nhân đã được xác định có đột biến BRCA1/2 dạng di truyền hoặc mắc phải nguy hiểm hoặc nghi ngờ nguy hiểm. Bệnh nhân UTBT giai đoạn III, IV đã phẫu thuật tổng khối tế bào bướu trước hoặc xen kẽ trong thời gian hóa trị. Bệnh nhân giai đoạn IV có thể được chỉ định sinh thiết hoăc được phẫu thuật. Bệnh nhân có đáp ứng hoàn toàn hoặc một phần về lâm sàng sau điều trị hóa chất có chứa Platinum (không có Bevacizumab). Đáp ứng hoàn toàn: không còn bằng chứng của bệnh trên chẩn đoán hình ảnh + nồng độ $\mathrm{CA}-125$ bình thường. Đáp ứng một phần: giảm $\geq 30 \%$ thể tích u (so sánh từ lúc bắt đầu đến lúc kết thúc hóa trị) hoặc không có bằng chứng về u trên chẩn đoán hình ảnh nhưng CA - 125 cao hơn giới hạn bình thường trên. Bệnh nhân được cung cấp đầy đủ thông tin và chấp thuận tham gia nghiên cứu.

Thiết kế nghiên cứu và can thiệp: Đây là 
một thử nghiệm lâm sàng pha 3, ngẫu nhiên, có đối chứng, mù kép thực hiện tại 15 quốc gia.

Những bệnh nhân hoàn thành hóa trị được chỉ định ngẫu nhiên vào 1 trong 2 nhóm: nhóm nhận Olaparib viên nén (liều 300mg 2 lần/ngày) và nhóm nhận giả dược (placebo) theo tỷ lệ 2:1. Thử nghiệm được tiến hành cho đến khi bệnh tiến triển trên hình ảnh (theo tiêu chuẩn đánh giá đáp ứng đối với khối u đặc cải tiến - RECIST phiên bản 1.1) với điều kiện: bệnh nhân phải có lợi khi điều trị và không có chỉ định ngừng điều trị. Bệnh nhân không có bằng chứng bệnh tại thời điểm 2 năm sẽ ngừng điêu trị. Bệnh nhân không tái phát bệnh sau 2 năm sẽ ngừng can thiệp. Bệnh nhân có đáp ứng lâm sàng 1 phần sau 2 nằm được tiếp tục nhân can thiệp theo cách thức mù. Sự chuyển đổi giữa các nhóm điều trị không được chỉ định trong nghiên cứu. Sau khi kết thúc thử nghiệm, người bệnh được tiếp tục điều trị theo quyết định của điều tra viên.

Kết cưc của nghiên cứu: Tiêu chí chính của nghiên cứu là thời gian sông thêm bệnh không tiến triển (PFS) được đánh giá bởi nghiên cứu viên. PFS được định nghĩa là khoảng thời gian từ lúc lựa chọn ngẫu nhiên đến khi bệnh tiến triển khách quan trên chẩn đoán hình ảnh (theo RECIST 1.1) hoăc tử vong do bất kỳ nguyên nhân gì. Bệnh nhân được chụp cắt lớp vi tính và cộng hưởng từ hạt nhân tại thời điểm ban đầu, mỗi 12 tuần cho đến hết 3 năm và sau đó mối 24 tuần cho đến khi bệnh tiến triển.

Tiêu chí phụ bao gồm: thời gian sống bệnh không tiến triển lần thứ 2 (PFS2) (thời gian từ lúc lựa chọn ngẫu nhiên cho đến khi bệnh tiến triển lần 2 hoặc tử vong); thời gian sống thêm toàn bộ (OS); thời gian từ lúc lựa chọn ngẫu nhiên đến lần điều trị thứ 2 hoặc tử vong và chất lượng cuộc sống liên quan đến sức khỏe (sử dụng điểm chỉ số kết quả can thiệp - TOI (Trial Outcome Index Score) trong bộ câu hỏi đánh giá chức năng của liệu pháp điều trị ung thư buồng trứng (FACT-O)).

Những tác dụng bất lợi được cho diểm sử dụng Tiêu chuẩn tác dụng bất lợi thường gặp của Viên Ung thư quốc gia phiên bản 4.0.

Phẩn tích thống kê: Nhóm nghiên cứu xác định với 206 biến cố sẽ tạo ra độ mạnh 90\% cho thử nghiệm (với kiểm định 2 phía 0,05). Từ đó, thể hiện sự khác biệt có ý nghĩa thống kê về PFS giữa nhóm điều trị Olaparib và nhóm giả dược. Tuy nhiên, do tỷ lệ biến cố thấp hơn dự kiến nên nhóm nghiên cứu đã điều chỉnh lại và sẽ thực hiện phân tích kết quả tại thời điểm có khoảng 196 biến cố (độ trưởng thành dữ liệu xấp xỉ
50\%) hoặc 03 năm sau khi bệnh nhân cuối cùng được lựa chọn (bất kể điều nào đến trước).

\section{KẾT QUẢ NGHIÊN CỨU}

Các đặc điểm của đối tượng nghiên cứu có sự đồng đều giữa 2 nhóm. Tại thời điểm bắt đầu thử nghiệm, đa số người bệnh không có biểu hiện bệnh, toàn trạng tốt, nồng độ CA125 huyết thanh trong giới hạn bình thường.

Dựa trên đặc điểm đột biến gen BRCA: trung tâm xác nhận 388/391 người bệnh có đột biến BRCA1/2 di truyền; 1 bệnh nhân có gen BRCA dạng biến thể không có ý nghĩa và 2 bệnh nhân có đột biến BRCA1/2 mắc phải.

Trung vị của khoảng thời gian theo dõi là 40,7 tháng trong nhóm Olaparib và 41,2 tháng trong trong placebo. 123 bệnh nhân trong nhóm Olaparib (chiếm $47 \%$ ) và 35 bệnh nhân trong nhóm placebo $(27 \%)$ hoàn thành điều trị 2 năm theo protocol. Có 26 bệnh nhân nhóm Olaparib $(10 \%)$ và $3 \mathrm{BN}$ nhóm placebo (2\%) tiếp tục được điều trị sau 2 năm.

Hiệu quả của Olaparib. Phân tích tiêu chí chính được thực hiện khi 198/391 bệnh nhân được nghiên cứu viển đánh giá là có bệnh tiến triển hoăc tử vong (độ trưởng thành dữ liệu $51 \%)$. Kiểm định Kaplan - Meier ước tính tỷ lệ sống bệnh không tiến triển hoặc tử vong tại thời điểm 3 năm là $60 \%$ ở nhóm Olaparib so với $27 \%$ ở nhóm placebo (HR của PFS là 0,3;95\% CI: $0,23-0,41 ; p<0,001)$ (Bî̀u đồ 1A). Trung vị PFS tính từ lúc kết thúc hóa trị là 13,8 tháng ở nhóm placebo.

Theo phân tích về PFS đánh giá bởi một trung tâm độc lập (có làm mù) (độ trưởng thành dữ liêu $38 \%$ ), test Kaplan - Meier ước tính tỷ lệ sống bệnh không tiến triển hoặc tử vong sau 3 năm là $69 \%$ ở nhóm Olaparib, so với $35 \%$ ở nhóm giả dược (HR của PFS là 0,28; 95\% CI: 0,20 0,39; $p<0,001$ ) (Biểu đồ 1B). Những kết quả này cũng phù hợp với lợi ích của Olaparib về cải thiện PFS đánh giá bởi nghiên cứu viên.

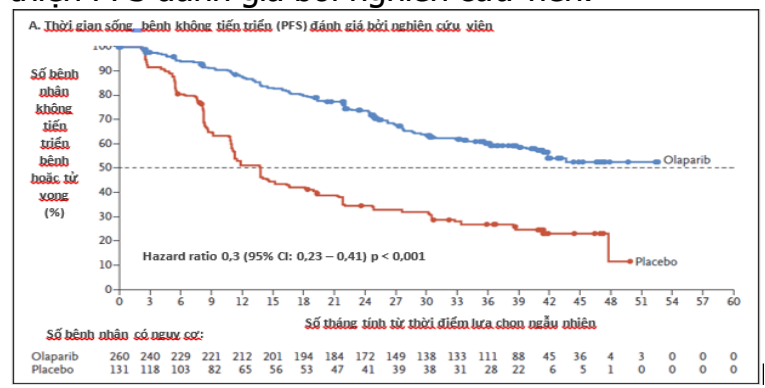

Khi phân tích về PFS2 (độ trưởng thành dữ liêu $31 \%$ ), test Kaplan - Meier ước tính tỷ lê sống bệnh không tiến triển lần 2 hoặc tử vong 
tại thời điểm năm thứ 3 là 75\% ở nhóm Olaparib so với $60 \%$ ở nhóm giả dược (HR của PFS2 là 0,50; 95\% CI: 0,35-0,72; p <0,001). Trung vị PFS2 là 41,9 tháng ở nhóm dùng giả dược.

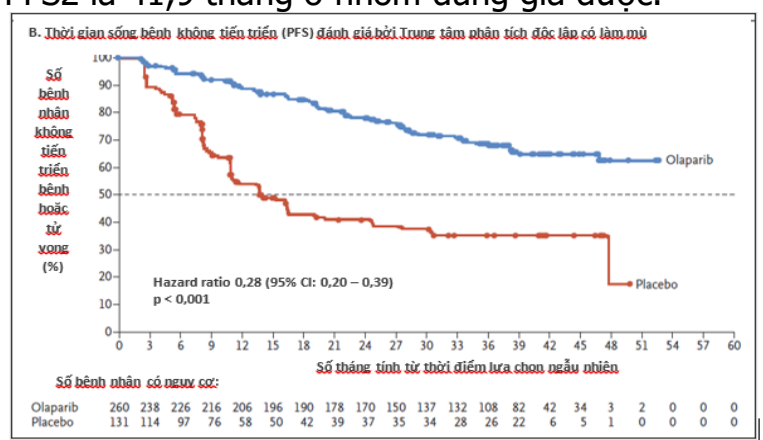

Biêu đồ 1. Thời gian sống bệnh không tiên triển ước tính bởi test Kaplan - Meier

Trong một phân tích giữa kỳ về OS (độ trưởng thành dữ liệu 21\%), test Kaplan - Meier ước tính tỷ lệ sống còn toàn bộ tại thời điểm 3 năm là $84 \%$ ở nhóm Olaparib và $80 \%$ ở nhóm placebo (hazard ratio =0,95; 95\% CI: 0,60 -
1,53). Trung vị thời gian tới lân điêu trị tiếp theo đâu tiên hoặc tử vong là 51,8 tháng ở nhóm Olaparib và 15,1 tháng ở nhóm giả dược (hazard ratio0,3; 95\% CI: 0,22 - 0,40). Test này cũng tính toán tỷ lệ không phải điêu trị lân hai hoặc không tử vong tại thời điểm 3 năm là $74 \%$ ở nhóm Olaparib trong khi nhóm placebo là $56 \%$ (hazard ratio 0,45; 95\% CI: 0,32-0,63). Trung vị khoảng thời gian đến khi điêuu trị lần hai hoặc tử vong ở nhóm giả dược là 40,7 tháng.

Tính an toàn. Biến cố ngoại ý thường gặp hâu hết là các biến cố độ 1 và độ 2 . Các biến cố ngoại ý nghiêm trọng xảy ra ở $21 \%$ bệnh nhân điều trị Olaparib và $12 \%$ bệnh nhân trong nhóm giả dược. Thiếu máu là biến cố nghiêm trọng hay gặp nhất. Tuy nhiên, trong suốt quá trình dùng Olaparib và kéo dài tới 30 ngày sau khi dừng thuốc, không có biến cố nào nghiêm trọng đến mức gây tử vong. Thiếu máu và buồn nôn là hai tác dụng phổ biến nhất khiến người bệnh phải dừng điều trị Olaparib.

Bảng 1. Tổng kêt các biến cố bất lợi

\begin{tabular}{|c|c|c|c|c|}
\hline \multirow{3}{*}{ Biến cố bất lợi } & \multicolumn{2}{|c|}{ Olaparib $(n=260)$} & \multicolumn{2}{|c|}{ Placebo $(n=130)$} \\
\hline & Mọi mức độ & Đố 3, 4 & Mọi mức độ & Độ 3, 4 \\
\hline & \multicolumn{4}{|c|}{ Số bệnh nhân (\%) } \\
\hline Mọi biến cố & $256(98)$ & $102(39)$ & $120(92)$ & $24(18)$ \\
\hline Buôn nôn & $201(77)$ & $2(1)$ & $49(38)$ & 0 \\
\hline Mệt mỏi, suy nhược & $165(63)$ & $10(4)$ & $54(42)$ & $2(2)$ \\
\hline Nôn mưa & $104(40)$ & $1(<1)$ & $19(15)$ & $1(1)$ \\
\hline Thiếu máu & $101(39)$ & $56(22)$ & $13(10)$ & $2(2)$ \\
\hline Tiêu chảy & $89(34)$ & $8(3)$ & $32(25)$ & 0 \\
\hline Táo bón & $72(28)$ & 0 & $25(19)$ & 0 \\
\hline Mất vị giác & $68(26)$ & 0 & $5(4)$ & 0 \\
\hline Đau khớp & $66(25)$ & 0 & $35(27)$ & 0 \\
\hline Đau bụng & $64(25)$ & $4(2)$ & $25(19)$ & $1(1)$ \\
\hline Giảm bạch câu hạt & $60(23)$ & $22(9)$ & $15(12)$ & $6(5)$ \\
\hline Đau đâu & $59(23)$ & $1(<1)$ & $31(24)$ & $3(2)$ \\
\hline Chóng mặt & $51(20)$ & 0 & $20(15)$ & $1(<1)$ \\
\hline Giảm cảm giác ngon miệng & $51(20)$ & 0 & $13(10)$ & 0 \\
\hline Đau bụng thượng vị & $46(18)$ & 0 & $17(13)$ & 0 \\
\hline Khó tiêu & $43(17)$ & 0 & $16(12)$ & 0 \\
\hline $\mathrm{Ho}$ & $42(16)$ & 0 & $28(22)$ & 0 \\
\hline Đau lưng & $40(15)$ & 0 & $16(12)$ & 0 \\
\hline Khó thớ & $39(15)$ & 0 & $7(5)$ & 0 \\
\hline Hạ tiếu câu & $29(11)$ & $2(1)$ & $5(4)$ & $2(2)$ \\
\hline
\end{tabular}

Chất lượng cuộc sống. Điểm chỉ số kết quả can thiệp (TOIS) trung bình tại thời điểm bắt đầu điều trị ở nhóm Olaparib là 73,6, nhóm giả dược là 75. Điểm số này giữ ổn định trong nhóm Olaparib, thay đổi trung bình 0,3 điểm sau 2 năm (CI $95 \%=-0,72$ đến 1,32) so với 3,3 điểm ở nhóm giả dược (CI $95 \%=1,84$ đến 4,76). Ước tính khác biệt trong sự thay đổi giữa 2 nhóm là -
3,00 điểm (CI 95\% =- 4,78 đến - 1,22) tuy vậy sự khác biệt chưa có ý nghĩa thống kê.

\section{BÀN LUẬN}

Như vậy, trong thử nghiệm SOLO1 pha 3, liệu pháp điêu trị duy trì bằng Olaparib đã đem lại lợi ích đáng kể liên quan đến cải thiện PFS ở những phụ nữ mới được chẩn đoán UTBT tiến xa có đột biến gen BRCA 1/2, làm giảm 70\% nguy cơ bệnh 
tiến triển hoặc tử vong so với giả dược. Trung vị sự khác biệt PFS giữa 2 nhóm xấp xỉ 3 năm. Trung vị PFS ở những phụ nữ dùng giả dược là 13,8 tháng (tính từ thời điểm kết thúc hóa trị liệu), phù hợp với kết quả của các nghiên cứu sử dụng Paclitaxel + Carboplatin ở những phụ nữ mới được chẩn đoán UTBT tiến xa có đột biến gen BRCA. Sự cải thiện giá trị tuyệt đối PFS ở nhóm điều trị Olaparib so với giả dược trong nghiên cứu này cũng lớn hơn đáng kể so với những nghiên cứu sứ dụng thuốc ức chế PARP trong những trường hợp bệnh tái phát và một số người bệnh không phù hợp để dùng Olaparib như một biện pháp điều trị bước hai (ví dụ những người kháng Platinum). Nhiều bệnh nhân trong nghiên cứu này sau khi dừng can thiệp sau 2 năm đã không tiến triển bệnh trong nhiều tháng. Rõ ràng, chỉ có những bệnh nhân mới được chẩn đoán UTBT tiến xa, mới là nhóm bệnh nhẩn có khả năng chữa khỏi bệnh. Hầu hết người bệnh trong thử nghiệm này đều có đột biến gen BRCA1/2 dạng di truyền. Tuy nhiên, nhiều nghiên cứu khác cho thây: kết quả của can thiệp Olaparib có thể ứng dụng trên cả những người bệnh có đột biến BRCA1/2 mắc phải.

\section{KẾT LUÂNN}

Thử nghiệm SOLO1 đã cho thấy lợi ích đáng kể của Olaparib trong điều trị duy trì sau hóa trị liệu có Platinum, giúp cải thiện thời gian sống không bệnh tiến triển ở phụ nữ mới được chẩn đoán ung thư buồng trứng tiến xa có đột biến gen BRCA1/2.

\section{Tên viêt tắt:}

UTBT: Ung thư buồng trứng

HR: Hazard ratio - tỳ số nguy cơ

PARP: enzyme poly(adenosine diphosphate ribose) polymerase

OS: Overall Survival - Thời gian sống còn toàn bộ

PFS: Progression free survival - Thời gian sổng bệnh không tiến triển

RECIST 1.1: Response Evaluation Criteria In Solid Tumors version 1.1 - Tiêu chuẩn đánh giá đáp ứng khối u đă̆c bản 1.1

Tài liệu gốc: "Maintenance Olaparib in Patients with Newly Diagnosed Advanced Ovarian Cancer" Moore K et al. N. Engl. J. Med. 2018; 379:2495-505

Lời cảm ơn: Bài viết này được hố trợ từ AstraZeneca cho mục đích giáo dục y khoa.

\title{
THỰC TRẠNG KIẾN THỨC, THỰC HÀNH PHÒNG CHỐNG BÊNNH SỞI CỦA PHỤ NỮ MANG THAI TẠI THI XÃ TƯ SƠN, TỈNH BẮC NINH NĂM 2020 VÀ MộT SỐ YẾU TỐ LIÊN QUAN
}

\author{
Nguyễn Đăng Vững1, Trần Thanh Thủy ${ }^{1}$, Mai Thị Lan Hương ${ }^{2}$
}

\section{TÓM TẮT}

Điều tra mô tả cắt ngang trên 378 đối tượng tham gia nghiên cứu về kiến thức thực hành phòng chống bênh sởi của phụ nữ mang thai tại thi xã Từ Sơn, tỉnh Bẳc Ninh năm 2020 nhằm mô tả kiến thức và thực hành phòng chống bênh sởi của phụ nữ mang thai. Chọn mẫu theo phương pháp lập danh sách các đối tượing là phụ nữ có thai tai 4 xã, phường dựa trên sổ quản lý của cán bộ dân số và của chương trình chăm sóc sức khoẻ sinh sản từng xã, phường và điêuu tra toàn bộ số phụ nữ này. Kết quả nghiên cứu cho $94,2 \%$ đã nghe nói về bệnh sởi, chủ yếu từ nguồn thông tin đai chúng. $91 \%$ đối tượng biết bênnh sởi có khả năng lấy truyền; $85,4 \%$ biểt bệnh sởi lây theo đường hô hấp và 94,7\% đối tượng biết mức độ nguy

\section{${ }^{1}$ Trường Đại họ Y Hà Nọi,}

${ }^{2}$ TTYT thj xã Từ Sơn, Bắc Ninh

Chịu trách nhiệm chính: Nguyễn Đăng Vững

Email: vunghmu@gmai.com

Ngày nhận bài: 16.8.2021

Ngày phản biện khoa học: 18.10.2021

Ngày duyệt bài: 28.10.2021 hiểm của bênh sởi. Kiến thức phòng chống bệnh sởi của đối tượng nghiên cứu còn ở mức thấp, chỉ có 33,3\% đối tượng có kiến thức tốt. Kiến thức thực hành phòng chống bệnh sởi cũng chưa cao, chỉ có $23,8 \%$ các đối tượng có kiến thức thực hành tốt về phòng chống bệnh sởi.18,5\% đối tượng tham gia nghiên cứu có tiêm phòng sởi trước khi mang thai.

Từ khóa: Phụ nữ mang thai, bệnh sởi, Bắc Ninh.

\section{SUMMARY}

THE SITUATION OF KNOWLEDGE AND

PRACTICE FOR MEASURES PREVENTION OF MEPOSITIS OF PREGNANT WOMEN IN TU SON TOWN, BAC NINH PROVINCE 2020 AND SOME FACTORS

A cross-sectional descriptive survey is conducted on 378 subjects participating in the study on knowledge and practice of measles prevention among pregnant women in Tu Son town, Bac Giang province in 2020. Select subjects by using the method of making a list of pregnant women in 4 communes and wards, based on the management books of population officials and the reproductive health care program of each commune and ward and survey these women. 